\title{
Using Graphic Organizers (GOs) to Improve Writing Opinion Paragraph among Intermediate EFL Learners
}

\author{
Bahman Gorjian \\ Associate Professor, Department of ELT, Abadan Branch, Islamic Azad University, Iran
}

\begin{abstract}
Graphic organizers (GOs) are a set of learning strategies which involve representation of information in visuals or graphics forms. When written material or difficult concepts are expressed graphically, the students can develop alternative structures for understanding the course concepts. The study intended to investigate the efficacy of using graphic organizers to enhance writing opinion paragraphs among Iranian intermediate EFL learners. In addition, it aimed to explore whether using graphic organizers causes differential effects among Iranian male versus female intermediate learners. To this end, Among the EFL learners attending English learning courses at Islamic Azad University of Ahvaz-Iran, a total number of 72 learners were selected randomly and classified to an experimental and a control group. The results indicated that employing activities using graphic organizers in EFL writing classes may help intermediate EFL learners to ameliorate ability of writing opinion paragraph.
\end{abstract}

Keywords: Graphic organizers, Opinion paragraphs, Semantic mappings, Gender 